\title{
Enhancement of circular RC columns using steel mesh as internal or external confinement under the influence of axial compression loading
}

\author{
Mohamed Emara \\ Structural Engineering Dept., Faculty of Engineering, Zagarig University, Zagarig, 44519, Egypt \\ mremara@eng.zu.edu.eg, http:/ /orcid.org/0000-0003-4936-5257
}

Mostafa S. Rizk

EL-Arish High Institute for Engineering and Technology, EL-Arish, North Sinai, Egypt

mostafasalah@zu.edu.eg, https://orcid.org/0000-0002-9026-897X

Heba A. Mohamed, Mahmoud Zaghlal

Structural Engineering Dept., Faculty of Engineering, Zagarig University, Zagarig, 44519, Egypt

hebawabbe@zu.edu.eg, bttps://orcid.org/0000-0002-8292-720X

myazagblal@zu.edu.eg, bttps://orcid.org/0000-0003-2579-6132

ABSTRACT. Reinforced concrete (RC) columns cannot get supreme confinement by using the customary steel stirrups reinforcement because of the requirements for the spacing distances between the stirrups in addition to concrete continuance problem. For this, Steel Mesh (SM) externally wrapped around the outer perimeter of the column as contributory confinement is being widely used due to its features. Limited tests focused on using SM for the internal confinement around the reinforcing cage of RC columns. Moreover, no experimental comparison was presented between RC columns internally and externally confined using SM. This paper investigates experimentally the behavior of circular RC columns confined internally or externally by SM. Six short RC columns have been subjected to axial loading until failure. The main studied parameters were SM schemes, number of SM wraps, SM position (internally or externally), and the steel stirrups existence. Results demonstrated that SM could decrease the crack opening, diminish the concrete spalling, increase the maximum failure load, and enhance the ductility, energy absorption, and column stiffness. Furthermore, the partial internal confinement using two wraps of SM around the steel ties presented the maximum capacity with reasonable ductility. In general, internally confined columns showed better behavior than the externally confined one.

KEYWORDS. RC Columns; Steel mesh; Internal confinement; External confinement; Axial loading.

\section{OPEN ACCESS}

Citation: Emara, M., Rizk, M. S., Mohamed, H. A., Zaghlal, M., Enhancement of circular RC columns using steel mesh as internal or external confinement under the influence of axial compression loading, Frattura ed Integrità Strutturale, 58 (2021) 86-104.

Received: 26.05 .2021 Accepted: 26.07.2021 Published: 01.10.2021

Copyright: (C) 2021 This is an open access article under the terms of the CC-BY 4.0, which permits unrestricted use, distribution, and reproduction in any medium, provided the original author and source are credited. 


\section{INTRODUCTION}

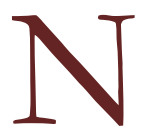

umerous strategies of the bending retrofitting for reinforced concrete (RC) elements were presented, such as bonded high strength fiber reinforced-polymer (FRP) sheets and steel plates on the outside of the concrete, and near-surface mounted (NSM) reinforcement using FRP or steel bars [1-6]. Even though these strategies have demonstrated efficiency in enhancing the bending strength of RC elements, each strategy has its drawbacks, NSM causes negative influences on the adjacent concrete. Bonded FRP strips and steel plates on the outside of the concrete are exposed to debonding problems from the external surfaces of concrete. Moreover, weak resistance to fire was noticed in the technique of externally bonded FRP that produces harmful vapors in the fire [7]. FRP materials are also broadly used in columns strengthening and repair because of their easy handling and lightweight. Many previous researches have demonstrated that the columns, which confined using FRP showed an improvement in their ductility and compressive strength [8-11]. Notwithstanding, due to the high industrialization and implementation costs of FRP materials, other confinement materials have been verified [12].

Steel Mesh (SM) is a favorable material that is being utilized as another method for column strengthening because of its features such as lightweight, satisfactory fire resistance, low cost, high strength, fast execution, and no need for skilled workers $[7,13]$. Prior researches have demonstrated that using SM as circumferential confinement for RC columns increases the strain value at the failure and the column ductility, and distributes stress regularly. Additionally, SM boosts the capacity of energy absorption and changes the mode of failure from a brittle pattern to a ductile one [14-17].

Kim and Choi [18] examined a repairing technique for deteriorated RC columns due to the earthquake. Three columns were initially exposed to the periodic load, and then the repairing technique was applied by wrapping Steel Wire Mesh (SWM) around the columns. After that, the tested columns were re-exposed to an earthquake load similar to an actual one. The results proved that the SWM has a mightily effective repair technique for RC columns that have insufficient lap splices under earthquake load, where the peak load, flexural strength, energy dispersion, stiffness, and the displacement ductility of the rehabilitated columns were larger than those of the unrepaired columns.

Kim and Kim [19] tested RC bridge columns retrofitted using SM and a porous polymer mortar. This study indicated that the improvement in the retrofitted columns ductility was greatly satisfactory, and their seismic behavior was extremely enhanced compared to the original columns without SM. Nevertheless, this retrofitting technique (with SM in addition to polymer mortar) has some defects. For instance, the polymer mortar possesses a slight ability to control the cracks, which leads to reduce the RC elements' toughness.

Abo-Alanwar [20] suggested a new procedure to strengthen twenty-one rectangular RC columns under the effect of eccentric compression represented in using various dimensions of steel plates and/or steel angles wrapped with SWM at the outer compression side. The results of this strengthening procedure showed that augmentation of the dimensions of steel plates and steel angles leads to a high increase in the maximum capacity and remarkable amelioration in the ductility for the retrofitted columns. Furthermore, in the case of the strengthened columns, steel plates and/or steel angles could carry forces from the peak loads more than steel reinforcement. Kumar and Patel [21] tested several numbers of concrete column specimens strengthened using Stainless Steel Wire Mesh (SSWM) under compression to evaluate the effectiveness of SSWM in the strengthening. It was noticed that when column specimens were strengthened using single and double layers of SSWM, the increase in the compressive strength reached $61 \%$ and $86 \%$, respectively. Additionally, the strengthened specimens showed lower lateral displacements and higher ultimate load than the unstrengthened specimens because of the confinement effect using SSWM, which was more economical compared to using FRP.

El-Kholy and Dahish [22] proposed an actual confinement arrangement consisted in using one layer of expanded mesh that was warped over the stirrups, which were used with different volumetric ratios in square RC columns. The confined columns showed higher plastic deformation, larger failure load, superior ductile performance, a greater capacity of energy absorption, and a larger decrease in the stirrups volumetric ratio compared to the unconfined columns.

El-Kholy et al. [23] studied experimentally several short square RC columns confined with two types of steel meshes; welded mesh and expanded mesh. Post-heating and preloading were taken into consideration in this test to simulate the fire and natural conditions to obtain an actual evaluation for the suggested confinement. The results confirmed that the metal meshes increased the ductility, failure load, and fire resistance of the confined columns compared to the unconfined columns. Due to the high strength of welded mesh, the influence of expanded mesh was lower than welded mesh on the loading capacity enhancement of the confined columns.

Marthong et al. [24] presented an experimental test on various column forms represented in rectangular, square, circular, and polygon shapes confined using SWM under the effect of axial loading. The findings of this test showed a noticeable 
increase in ultimate load, displacement ductility, stiffness, energy dissipation, and deformation in all wrapped columns compared to their control columns. The highest and the lowest load values were observed in the circular and polygon columns, respectively, which refers to the effect importance of the shape parameter of the confined columns on the load capacity.

Elsamny et al. [25] investigated theoretically and experimentally the performance of the strengthened deteriorated RC columns with various slenderness and aspect proportions. The columns were confined externally using both spiral stirrups and SWM, then covered by grout mortar. The proposed strengthening pattern contributed to increasing the columns carrying capacities and decreasing the transverse displacements. Additionally, the failure location was changed from the midheight of the column to its upper and lower parts or both after applying the proposed reinforcement technique. The used strengthening pattern was not affected by changing the slenderness proportions.

In addition, numerous tests were performed on RC beams strengthened using SWM in shear or in flexure/bending. The results confirmed that SWM could improve shear and flexural behaviors for the beams and enhance the beam flexibility. Moreover, using SM increased the peak load of the beam and its ultimate deflection [26- 29].

As noted in the literature, the research work utilized the Steel Mesh (SM) around the outer perimeter of the column as extra confinement. There are limited tests about using SM for the internal confinement around the ordinary steel stirrups of RC columns, especially the circular columns. No experimental comparison was presented between using the steel mesh as internal confinement around the reinforcing cage and using it as external confinement around the outer surface of the column. This requires the submission of new studies to establish the advantages of this confinement technique for the columns. This paper tested circular short RC columns confined internally or externally by SM subjected to axial loading to evaluate the effect of applying SM as transverse reinforcement on the column's performance. The influence of new parameters such as SM schemes, number of SM wraps, the volumetric ratio of the lateral confining reinforcement including lateral reinforcement (stirrups) and SM reinforcement, SM position (internally or externally), and the steel stirrups' existence was considered in this research. For comparison, there is an unconfined column as a reference specimen. The parameters influence in terms of mode of failure and crack pattern, load-vertical shortening curve, maximum load, ductility index, the capacity of energy absorption, and the stiffness were studied.

\section{EXPERIMENTAL STUDY PROGRAM}

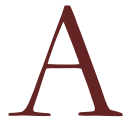
s stated above, the literature review has indicated the requirement for additional investigation about the employment of SM for the internal reinforcement around the ordinary steel stirrups in the circular RC columns. For this, the current paper investigates the behavior of circular concrete columns, confined using SM, under centric axial loads. The specimens details and test approach, material properties, and specimens preparation, including particular circular formworks, and concrete blending and casting, as well as loading configuration, and test setup for the current experimental study, are presented in the next sections.

\section{Specimens details and test approach}

In the present experimental program, six short circular steel-reinforced columns subjected to central static load were tested. All the prepared columns possess analogous cross-sections of $200 \mathrm{~mm}$ in diameter and $1000 \mathrm{~mm}$ in height as a small scale from the real column. The dimensions of the RC columns were selected according to the Egyptian code for design and construction of concrete structures (ECP 203/2010) [30] which recommended that the column diameter shall not be less than $200 \mathrm{~mm}$ for the circular section with a height at least five times the cross-sectional diameter. The experimental program was designed as follows: one column was kept as a control specimen without confinement, as shown in Fig. 1, with a volumetric ratio of the lateral reinforcement of $0.513 \%$. Three more columns were internally reinforced and confined using two different schemes; partial confinement with one and two wrapping layers of SM with $325 \mathrm{~mm}$ length at the top and bottom of the specimen, as indicated in Fig. 2, with a volumetric ratio of the lateral confining reinforcement of $0.578 \%$ and $0.645 \%$, respectively, and full confinement with a single wrap of SM material along the height of the reinforcing cage, as shown in Fig. 3, with a volumetric ratio of $0.609 \%$. The overlap length of the wrapped steel mesh reinforcement was $70 \mathrm{~mm}$; Fig. 4.

The last two specimens were fully confined using one SM layer along the column height; one specimen internally fully confined with SM material around the full height of the main reinforcing bars (about $0.24 \%$ volumetric ratio) instead of the ordinary steel stirrups (without stirrups) to investigate the confinement influence of SM and its extent of compensation for using the stirrups in the columns, as indicated in Fig. 5. The circular profile of steel mesh was maintained using $6 \mathrm{~mm}$ 
circular steel stirrups at both ends and mid-height of the main reinforcement for keeping the circular shape of the reinforced cage, and consequently the steel mesh; Fig. 5. whereas the other specimen externally fully confined with SM material around the full height of the outer perimeter of the column with total a volumetric ratio of the lateral confining reinforcement of $0.621 \%$. Initially, the surface of the circular column specimen was roughened, then the SM layer was wrapped around the specimen surface, and the endings of the wrapping layer were firmly tied to each other using a tying steel wire. Finally, a $20 \mathrm{~mm}$ thickness cement mortar layer with a ratio of 1:2, (cement to sand) was utilized to bond SM to the concrete surface and to envelope SM to protect it from the environmental effects; Fig. 6.

To maintain the SM position during concrete casting, the wrapped SM layers were tied to the lateral stirrups and main reinforcement in the case of the internal confinement by using tying steel wire, as shown in Fig. 7 . Thus, the space between the longitudinal bars and the mesh became very small and has no negative effect.

Six vertical steel bars with a diameter of $12 \mathrm{~mm}$ were utilized for the longitudinal reinforcement for all the samples. $8 \mathrm{~mm}$ steel stirrups were utilized, in five columns, for the transverse reinforcement at $180 \mathrm{~mm}$ spacing. Transverse and longitudinal reinforcements of the tested columns were adopted according to ES 262-1/2009 [31] and ES 262-2/2009 [32], respectively. The stirrups were installed around the vertical bars after leaving a $25 \mathrm{~mm}$ distance from the ends of the bars. The dimensions of the tested specimens and their reinforcement details are shown in Fig. 8. Additionally, the lengths of SM wraps in the partial and full confinement of the columns are illustrated in Fig. 9.

Tab. 1 presents the full details of the prepared column specimens and their confinement specifications. Each specimen was identified using letters and numbers as follows: the letter $\mathrm{C}$ at the beginning of the label symbolizes the matrix type, which here is conventional (Normal) concrete. The next two letters S and F refer to the SM schemes; S for strip (partial) internal confinement over the traditional stirrups and $\mathrm{F}$ for full confinement whether this confinement is internally over the entire reinforcing cage height or externally around the full height of the outer column perimeter. The first number (if any) in the specimen label denotes the SM wraps number. The next two letters OC at the end of the specimen label indicate that the SM layers have been wrapped around the outer core of the column (over the stirrups). While if the letters ED was found at the end of the specimen label, it means that the SM layers have been wrapped around the external diameter of the column as extra confinement (the outer perimeter of the column). Finally, the absence of the stirrups in the tested sample is expressed by adding the letter $\mathrm{W}$ to the specimen label.

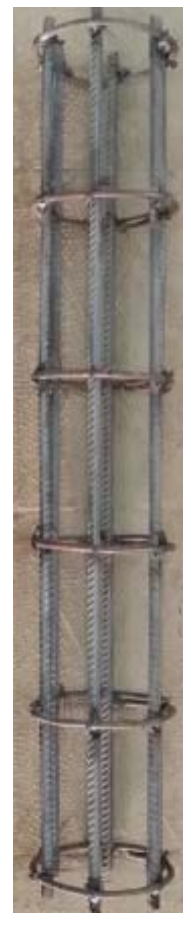

Figure 1: The column without confinement.

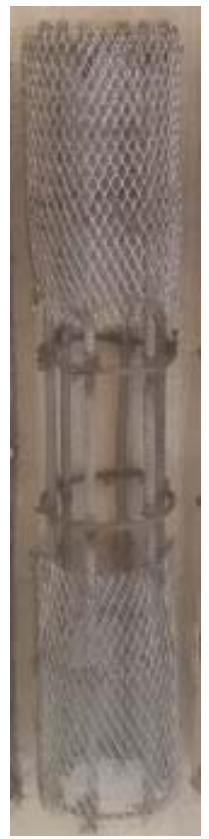

(a) Longitudinal view

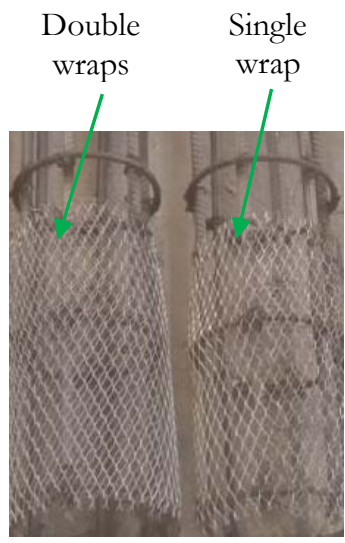

Figure 2: SM schemes (Partial internal confinement).

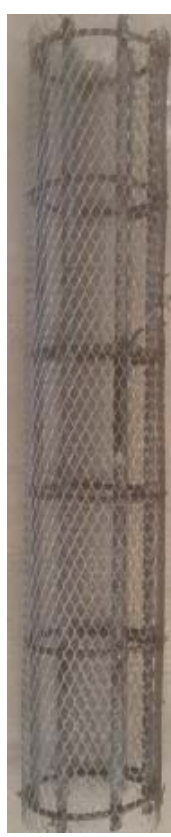

(a) Longitudinal view

(b) Cross-section view
Figure 3: SM schemes (Full internal confinement).

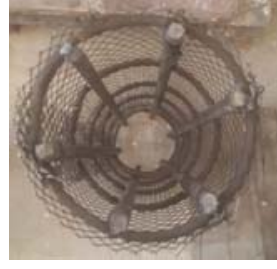

(b) Indication of the number of wraps 


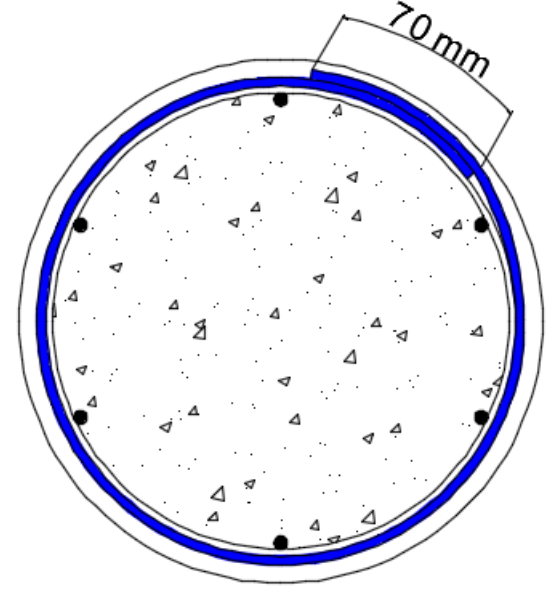

(a) Single layer of EMM

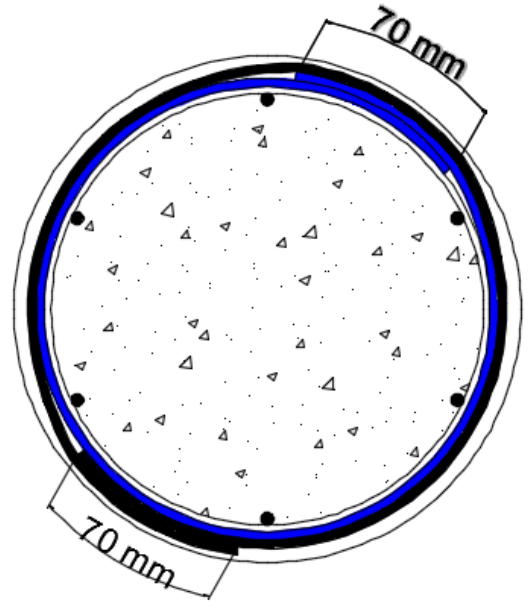

(b) Double layer of EMM

Figure 4: The lap in the single-layer and the double layer of mesh reinforcement. (Overlap length of EMM layer)

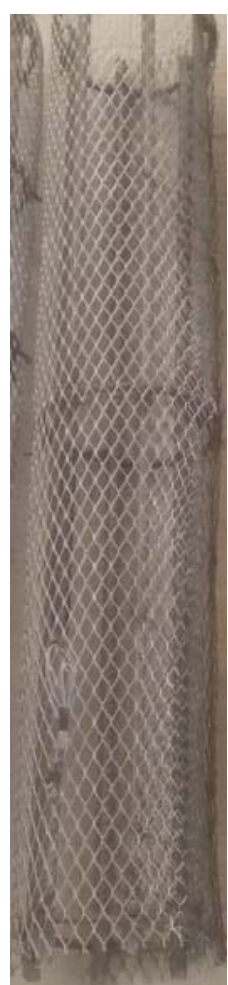

(a) Longitudinal view

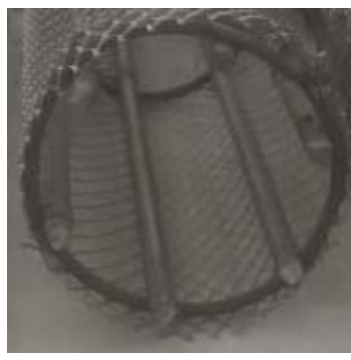
(b) Cross-section view

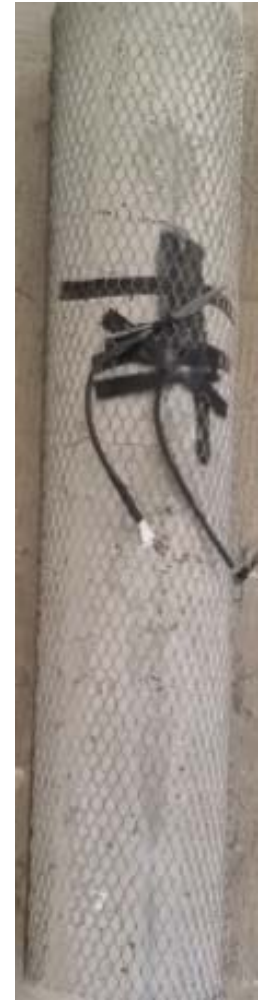

(a) Before using the cement mortar layer

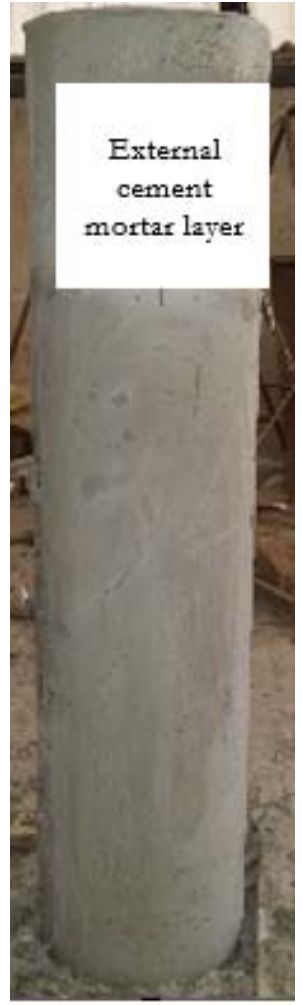

(b) After using the cement mortar layer tying SM layer to the stirrups and main

reinforcement using tying steel wire

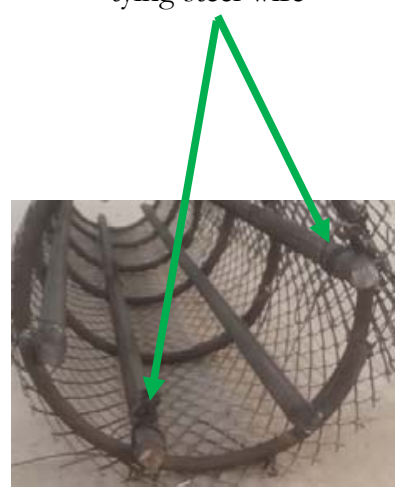

Figure 5: SM schemes (Full internal confinement but without stirrups). confinement).
Figure 7: Tying SM layer to the stirrups and main reinforcement. 


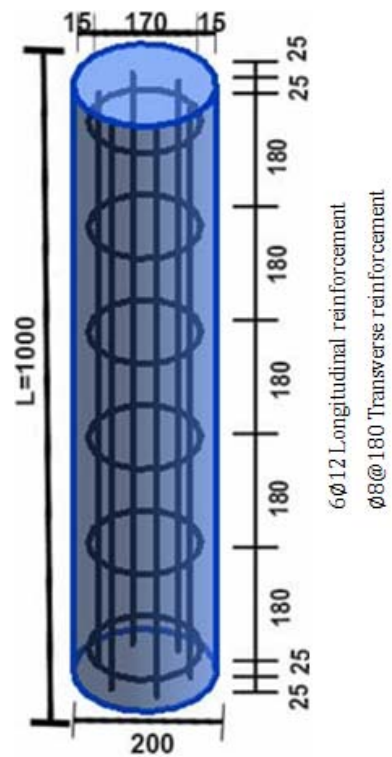

(a) The column in $3 \mathrm{D}$ view

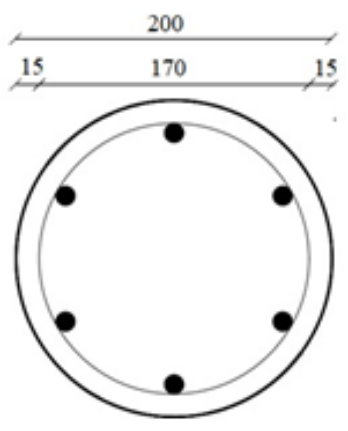

$6 ₫ 12$ Longitudinal reinforcement Ф8@180 Trans verse reinforcement

(b) Cross section

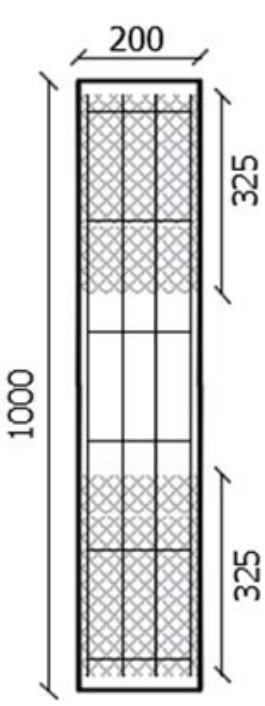

(a) partial confinement

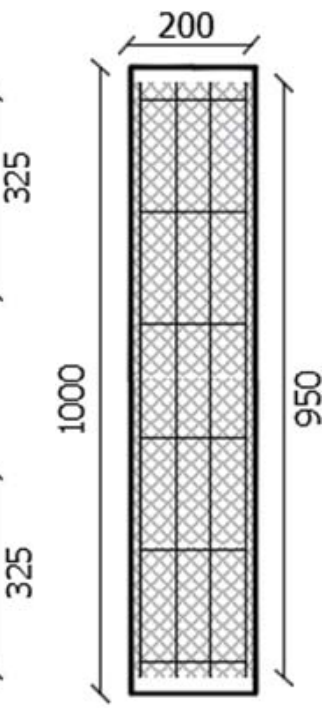

(b) Full confinement

Figure 8: Dimensions of the tested column specimens and their reinforcement details (dimensions in $\mathrm{mm}$ ).

Figure 9: The lengths of SM wraps (dimensions in $\mathrm{mm}$ ).

\begin{tabular}{|c|c|c|c|c|c|c|c|}
\hline $\begin{array}{c}\text { Specimen } \\
\text { NO }\end{array}$ & $\begin{array}{l}\text { Specimen } \\
\text { label }\end{array}$ & $\begin{array}{l}\text { Longitudinal } \\
\text { reinforcement } \\
\quad(\mathrm{mm})\end{array}$ & $\begin{array}{l}\text { Transverse } \\
\text { reinforcement } \\
\quad(\mathrm{mm})\end{array}$ & SM schemes* & $\begin{array}{l}\text { Number } \\
\text { of SM } \\
\text { wraps }\end{array}$ & $\begin{array}{c}\text { Volumetric } \\
\text { ratio of lateral } \\
\text { reinforcement } \\
\%\end{array}$ & $\begin{array}{l}\text { Height } \\
\text { of the } \\
\text { wraps } \\
(\mathrm{mm})\end{array}$ \\
\hline 1 & C CONTROL & $6 \emptyset 12$ & ø8@180 & - & - & 0.513 & - \\
\hline 2 & CS1OC & $6 \emptyset 12$ & Ø8@180 & $\begin{array}{l}\text { PC around upper \& } \\
\text { lower portion of OC } \\
\text { of the column sample }\end{array}$ & One & 0.578 & 325 \\
\hline 3 & $\mathrm{CS} 2 \mathrm{OC}$ & $6 \emptyset 12$ & Ø8@180 & $\begin{array}{l}\text { PC around upper \& } \\
\text { lower portion of OC } \\
\text { of the column sample }\end{array}$ & Two & 0.645 & 325 \\
\hline 4 & CFOC & $6 \emptyset 12$ & Ø8@180 & $\begin{array}{l}\text { FC around the full } \\
\text { height of OC of the } \\
\text { column sample }\end{array}$ & One & 0.609 & 950 \\
\hline 5 & CWFOC & $6 \emptyset 12$ & - & $\begin{array}{l}\text { FC around the full } \\
\text { height of OC of the } \\
\text { column sample }\end{array}$ & One & 0.24 & 950 \\
\hline 6 & CFED & $6 \emptyset 12$ & Ø8@180 & $\begin{array}{l}\text { FC around the full } \\
\text { height of ED of the } \\
\text { column sample }\end{array}$ & One & 0.621 & 950 \\
\hline
\end{tabular}

Note: $(*)$ "PC" denotes the partial confinement, "OC" denotes the outer core of the column, "FC" denotes the full confinement, and "ED" denotes the external diameter of the column.

Table 1: Full details of the specimens and their confinement specifications.

\section{Material properties}

Crushed stone with $14 \mathrm{~mm}$ maximum size and 2.78 specific gravity was used as coarse aggregate. The medium-sized sand, with 2.53 specific gravity and 2.91 fineness modulus, was utilized as fine aggregate. Both coarse and fine aggregates (crushed stone and sand) are compatible with the Egyptian Standards [33]. The Portland Cement, which has a strength grade of 42.5 $\mathrm{MPa}$ and identical to cement type 1 in the Egyptian Standards [34] and British Standards [35], was utilized in the preparation of the concrete admixture. 
The vertical bars and horizontal stirrups used in the column samples are high-strength steel and mild steel, respectively. The material properties of used steel bars, as well as stirrups, were listed in Tab. 2. Among available types of expanded metal mesh, the most two common types, which could be used for RC column confinement, are the standard expanded metal and the flattened expanded metal. In the current study, the standard expanded metal mesh was selected due to its versatility and economic characteristics. The mesh openings have a diamond shape with $15 \mathrm{~mm} \times 20 \mathrm{~mm}$ strand spacing and $1.6 \mathrm{~mm}$ diameter; Fig. 10.

The yield tensile stress, ultimate tensile stress, and elastic modulus of the EMM were obtained through the direct tensile test, which was conducted on coupon specimens cut from the metal mesh. The specimen was prepared by immersing the two ends of a metal mesh coupon in a mortar along a length equal to the specimen width; Fig. 11. Both ends were embedded in the mortar that acted as gripping pads and the test specimen was represented by the non-embedded part of the metal mesh. As recommended by Batson et al. [36], the test specimen has a width of $120 \mathrm{~mm}$ (at least six times the wire spacing) and a length of $360 \mathrm{~mm}$ (more than or equal to three times of specimen width); Fig. 11. After performing this tensile test on the EMM, it turned out that the EMM has $350 \mathrm{MPa}$ yield stress, $400 \mathrm{MPa}$ ultimate stress, and $185 \times 10^{3}$ MPa modulus of elasticity. The EMM was prepared in this research to be significantly spotless and free from detrimental/harmful materials like oil, rust, paint coating, dust, or analogous substances, as previously advised by Batson et al. [36].

The crushed stone was washed with pure water to obtain clean coarse aggregate before the blending, as indicated in Fig. 12. The target characteristic compressive strength of concrete considered for mixture design is $30 \mathrm{MPa}$. The ratio of the mixture by weight in the current study for concrete components including cement, fine aggregate, and coarse aggregate are 1, 1.63, and 3.79, respectively, as indicated in Tab. 3. For the existing experimental study, a water-cement ratio of 0.46 was considered. The slump test was performed during the concrete pouring process to ensure the desired workability of the concrete was achieved, as illustrated in Fig. 13, displaying a $77 \mathrm{~mm}$ slump value. As shown in Fig. 14, the concrete cubes of standard dimensions $(150 \times 150 \times 150 \mathrm{~mm})$ were cast, treated for 28 days, and then subjected to the compression test, displaying 30.67 MPa compressive strength.

\begin{tabular}{cccc}
\hline $\begin{array}{c}\text { Diameter } \\
(\mathrm{mm})\end{array}$ & $\begin{array}{c}\text { Yield stress } \\
\text { fy (MPa) }\end{array}$ & $\begin{array}{c}\text { Ultimate stress fu } \\
(\mathrm{MPa})\end{array}$ & $\begin{array}{c}\text { Modulus of elasticity } \\
\text { Es (GPa) }\end{array}$ \\
8 & 361 & 497 & 195 \\
12 & 531 & 640 & 204 \\
\hline
\end{tabular}

Table 2: Properties of reinforcing steel.

\begin{tabular}{ccccc} 
& Cement & Fine aggregate & Coarse aggregate & Water \\
Weight & $350 \mathrm{~kg} / \mathrm{m}^{3}$ & $568.77 \mathrm{~kg} / \mathrm{m}^{3}$ & $1327.13 \mathrm{~kg} / \mathrm{m}^{3}$ & $161 \mathrm{~kg} / \mathrm{m}^{3}$ \\
Ratio & 1 & 1.63 & 3.79 & 0.46 \\
\hline
\end{tabular}

Table 3: Mixture ratio designed for columns casting.

\section{Specimens preparation}

For the casting of the concrete mix in the vertical direction of the column-like construction in the site, particular circular formworks with $200 \mathrm{~mm}$ internal diameter and $1000 \mathrm{~mm}$ height were prepared and constructed, as shown in Fig. 15. The prepared formworks were vertically placed over horizontal circular bases of wood; Fig. 16. The designed reinforcing cage has been accurately positioned in the prepared formwork to start pouring of concrete. The components of the concrete mix have been designed to pass naturally from the column sample core through the expanded mesh's diamond openings using a mechanical vibrator to create the concrete cover of the sample without forming voids where the size of coarse aggregate is compatible with the mesh openings. For the blending of concrete components with the specified proportions, which previously mentioned, an electric mixer of concrete was utilized. For obtaining good concrete, an electric vibrator was used to consolidate the concrete and prevent the formation of voids in the column samples. Every column sample was extracted from its formwork after $24 \mathrm{~h}$ of casting then was wrapped using wet burlap for curing for 28 days. Finally, the samples were uncovered after the end of the curing period to dry at room temperature to be prepared for testing, as indicated in Fig. 17. 


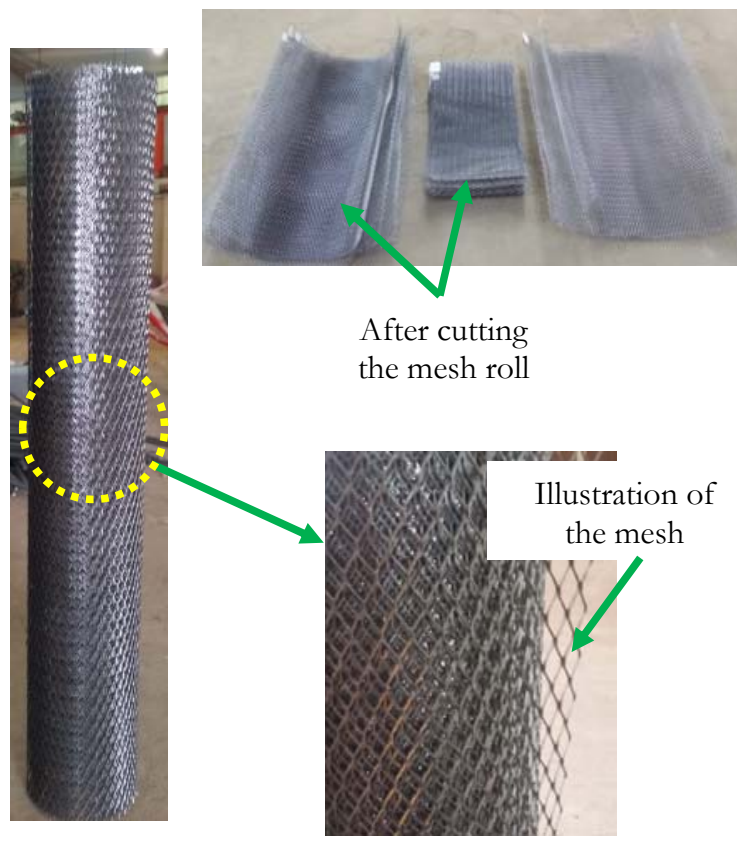

Figure 10: The used EMM with a diamond shape.
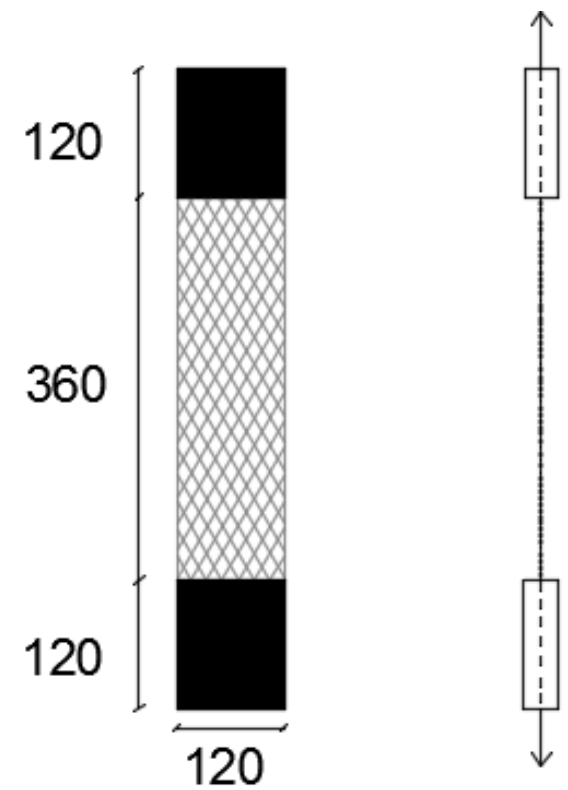

Figure 11: The used coupon specimens from the metal mesh for the direct tensile test (dimensions in $\mathrm{mm}$ ).

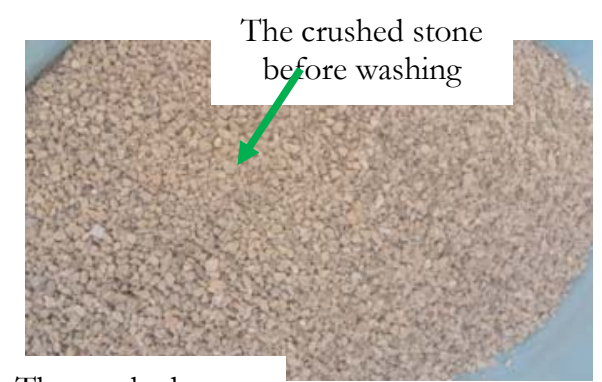

The crushed stone after washing

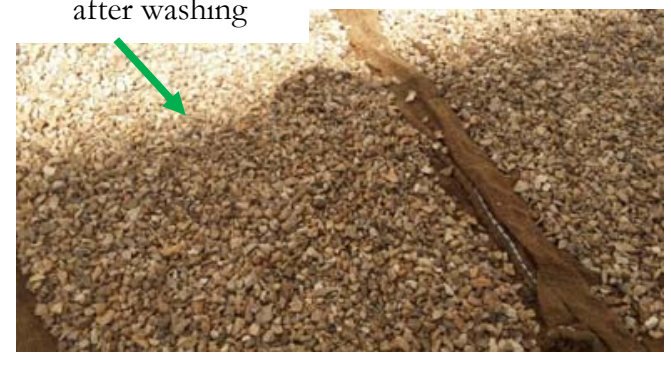

Figure 12: The used crushed stone.
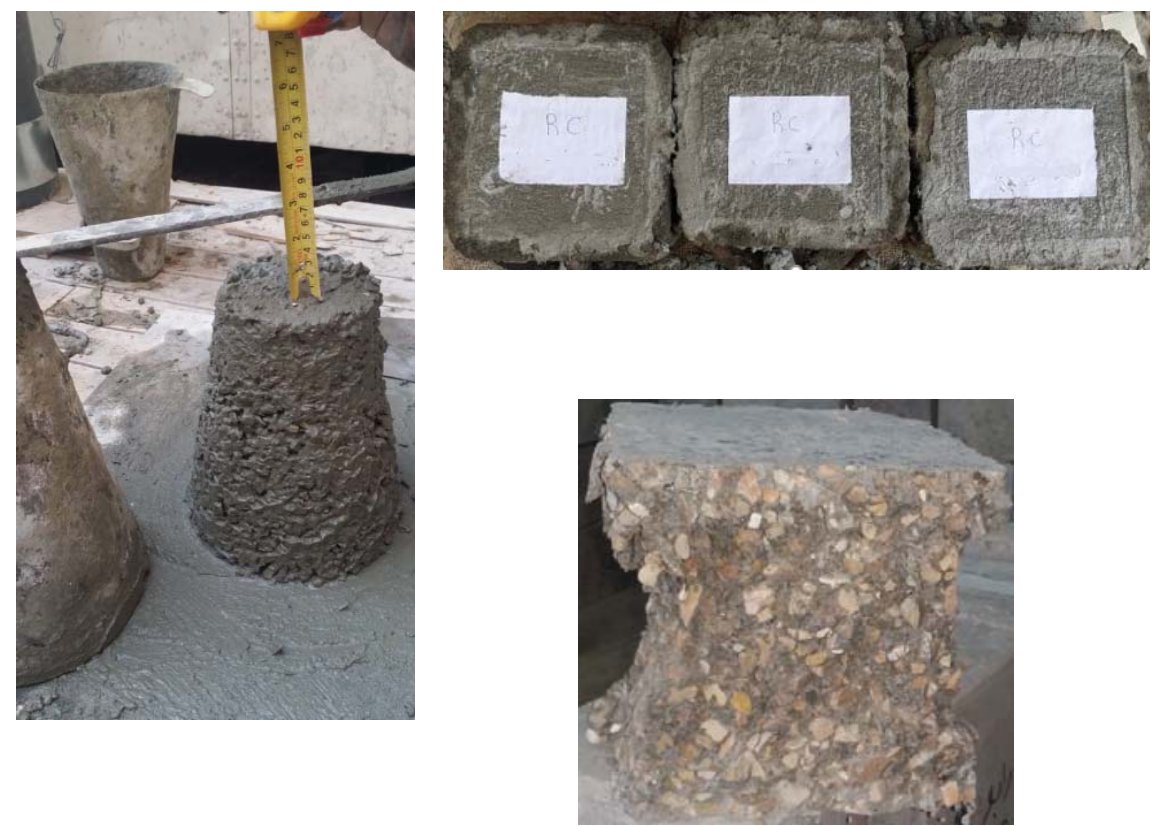

Figure 13: Slump test of fresh Figure 14: Cube specimens of compressive strength test. concrete. 


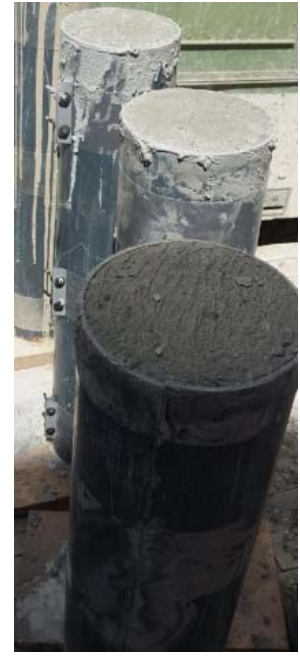

(a) Before concrete casting

(b) After concrete casting

Figure 15: The used formworks in the current test.
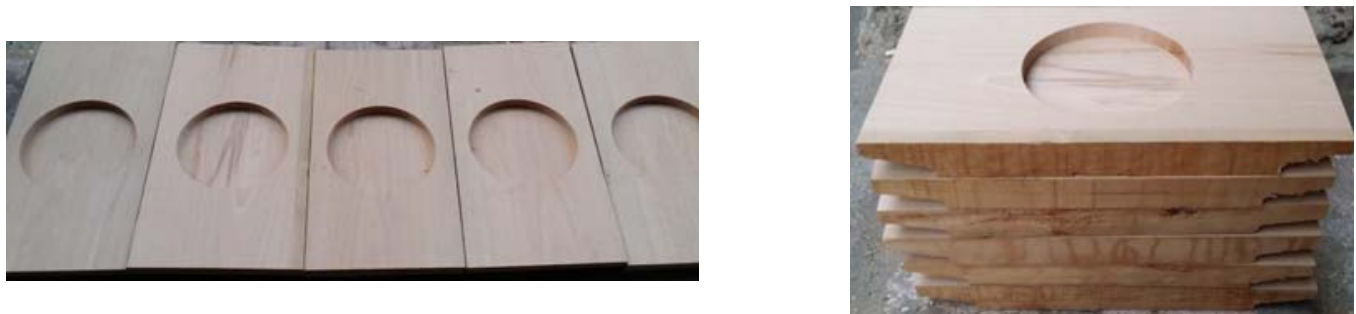

Figure 16: The prepared wooded circular bases.

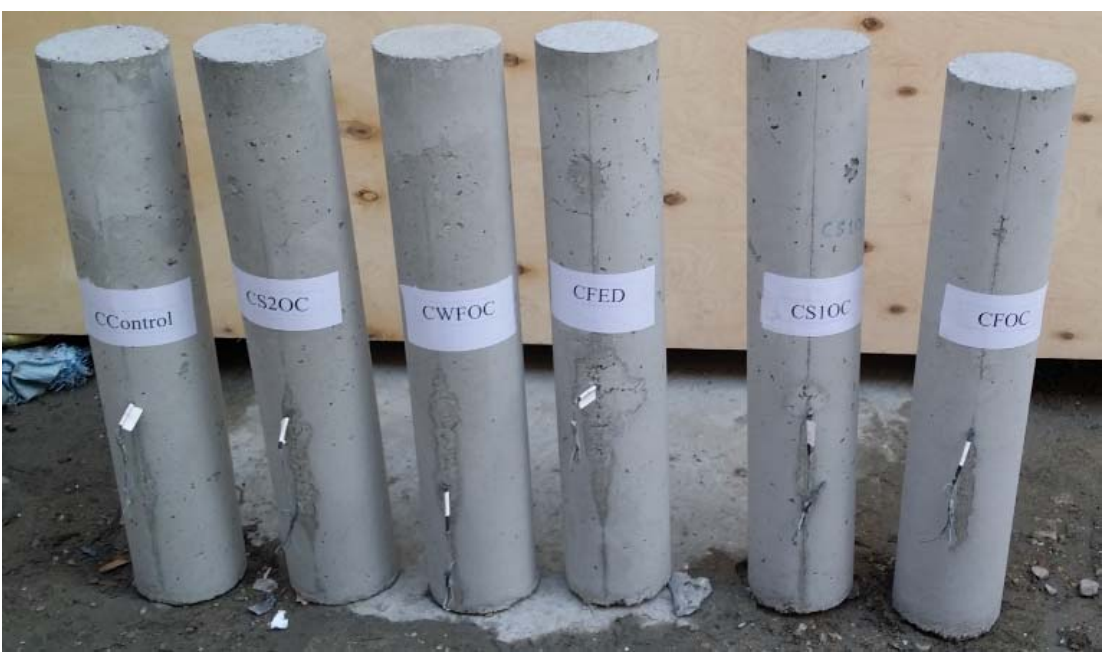

Figure 17: Column samples after drying.

\section{Loading configuration and test setup}

Fig. 18 shows the loading configuration and test setup. The hydraulic testing machine with a capacity of $2000 \mathrm{kN}$ was utilized for testing the desired column samples under the effect of centric loading. To guarantee the precision of the results, the machine was calibrated before testing. Stiff steel plates were installed below and over the column sample. Steel collar was coiled and bolted using high strength bolts around supporting and loading ends of the sample for adequate confinement; Fig. 19. The centric load at the failure was promptly determined using a load cell at the testing machine. To monitor the 
vertical shortening of the column sample at each loading step, a single displacement transducer, fixed to the steel base plate, was mounted at the vertical orientation of the sample over its entire height. Moreover, an electrical strain gauge was installed at the bottom third of the column height of every tested column specimen for measuring the vertical strain. The centric load, its corresponding displacement and axial strain were registered automatically using the data logger system.
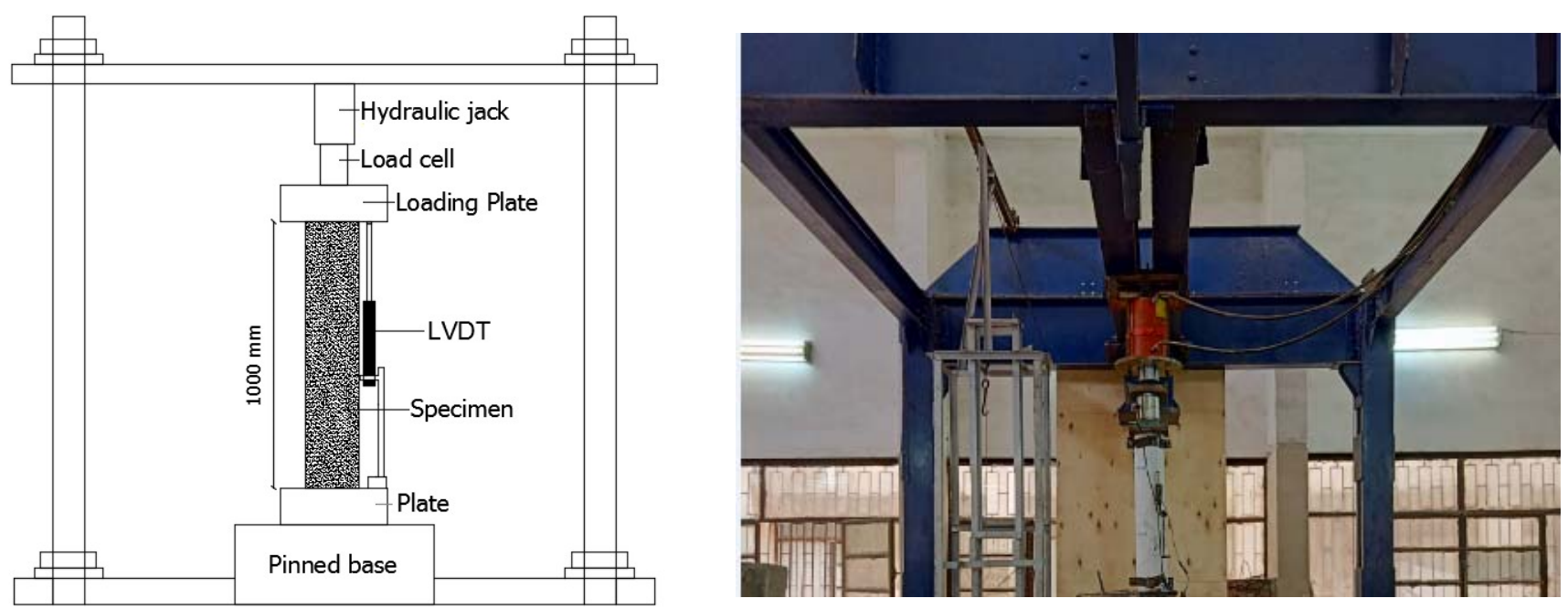

Figure 18: Loading configuration and test setup.
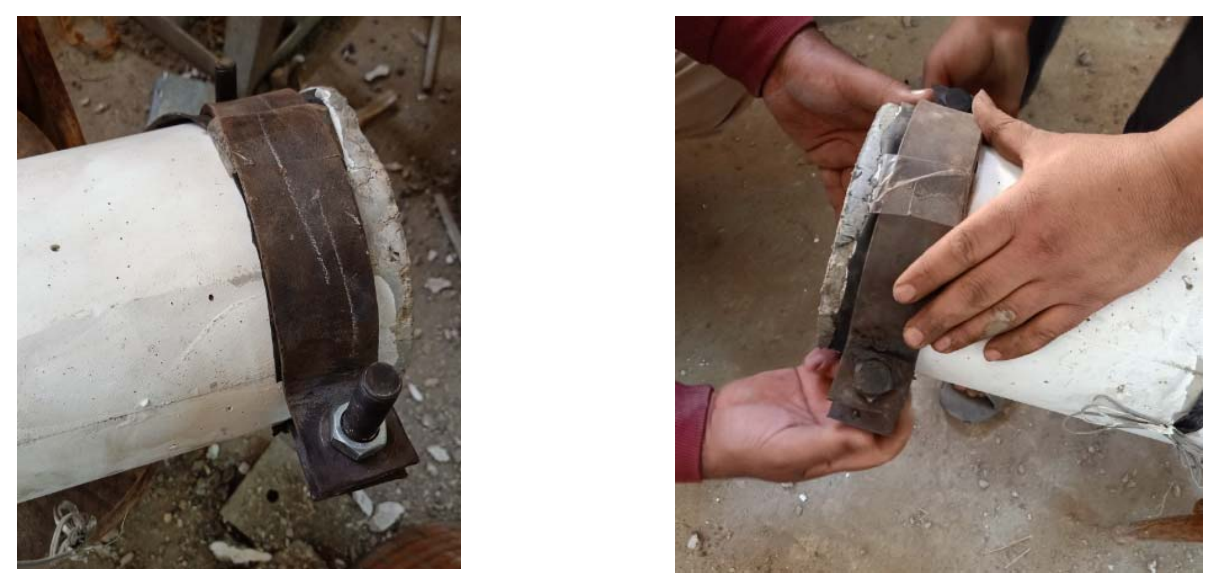

Figure 19: Steel collar at the ends.

\section{RESULTS AND ANALYSIS}

ab. 4 indicates the fundamental experimental outcomes for each tested column. The outcomes include the maximum load, axial shortening at both yield and ultimate loads, energy absorption, ductility index, and stiffness. Besides, this table shows the improvement of the maximum load over the control column specimen due to partial/full confinement using SM. Fig. 20 presents crack patterns and modes of failure for tested columns. Fig. 21 illustrates the comparison between the load-vertical shortening curve of the control specimen and that of the confined specimens under the effect of the studied parameters. Fig. 22 shows also a comparison between load-vertical shortening curves of full internal and full external confinement. Figs. 23, 24, 25, and 26 display the increases in maximum load, ductility index, energy absorption as well as stiffness, respectively, for the confined column specimens (with respect to the control column specimen). 


\section{Crack patterns and failure modes}

For all tested RC columns, vertical cracks began to appear in the longitudinal direction at about $70 \%$ of the column failure load. These cracks spread and became wider with rising the axial loading of the columns. As a result, the concrete cover spalling of the column samples was observed before reaching their ultimate capacity. Lastly, concrete crushing was noticed in many of the studied column samples at the bottom third of the sample height, and the ability to bear loads was dropped; Fig. 20. This is identical to the failure position of the tested columns by Kim and Choi [18] and Yanhua et al. [37].

The failure mode for the control specimen (C CONTROL) was a somewhat brittle failure, while the rest of the specimens showed a remarkable deformation capacity due to the help of internal or external jacketing using SM. It was found that the domain of concrete cover spalling or the deterioration level of concrete crushing at the failure was larger for the control column specimen (C CONTROL), which was confined using stirrups only, and for the column specimen (CWFOC), which was internally confined using only EMM as full confinement without stirrups, as indicated in Fig. 20 (a) and (e).

The partial confinement with a single wrap of EMM above the stirrups (internal confinement) as in specimen CS1OC showed a slight improvement in the deterioration degree of concrete crushing compared to the control RC column specimen at the loading end, as shown in Fig. 20 (b). Moreover, the use of two EMM layers as partial confinement around the stirrups or a single EMM layer as full confinement around the reinforcing cage significantly reduced the concrete cover spalling zone and diminished the severity of concrete crushing, as shown in Fig. 20 (c) and (d); for specimens CS2OC and $\mathrm{CFOC}$, respectively. This shows that the internally confined columns that have a higher volumetric ratio of lateral confining reinforcement enhance the confinement efficiency of the tested columns and present more ductile failure compared to the column specimens that have a lower volumetric ratio of lateral confining reinforcement. Consequently, using SM in addition to the stirrups gives better confinement. Rupture of some strands in the EMM was only observed in the specimen CS2OC, which achieved thef largest ultimate load.

Externally fully jacketing using a single wrap of EMM around the outer perimeter of the column presented effective confinement, where the spalling occurred in the external cement mortar layer around the steel mesh, and the internal core stayed intact, as well as the cracks did not permeate within the column, as shown in Fig. 20 (f), this represents an acceptable failure mode for the column element.

\begin{tabular}{ccccccccc}
\hline $\begin{array}{c}\text { Specimen } \\
\text { NO }\end{array}$ & Specimen label & $\begin{array}{c}\mathrm{P}_{\max } \\
(\mathrm{kN})\end{array}$ & $\begin{array}{c}\boldsymbol{\Delta}_{\mathrm{y}} \\
(\mathrm{mm})\end{array}$ & $\begin{array}{c}\boldsymbol{\Delta}_{\mathrm{u}} \\
(\mathrm{mm})\end{array}$ & $\mathrm{P}_{\max } / \mathrm{P}_{\text {C CONTROL }}$ & $\begin{array}{c}\text { Capacity of } \\
\text { energy absorption } \\
(\mathrm{kN} . \mathrm{mm})\end{array}$ & $\begin{array}{c}\text { Stiffness } \\
(\mathrm{kN} / \mathrm{mm})\end{array}$ \\
1 & C CONTROL & 680 & 2.84 & 3.27 & 1 & 1675.44 & 1.15 & 244.44 \\
2 & CS1OC & 748.2 & 2.63 & 3.39 & 1.1 & 3004.69 & 1.29 & 277.33 \\
3 & CS2OC & 788.2 & 2.35 & 3.11 & 1.16 & 4404.10 & 1.32 & 314.03 \\
4 & CFOC & 770.92 & 1.78 & 3.33 & 1.13 & 4392.69 & 1.78 & 369.52 \\
5 & CWFOC & 674.1 & 2.12 & 2.51 & 0.99 & 1996.23 & 1.18 & 305.48 \\
6 & CFED & 749.73 & 1.96 & 3.23 & 1.103 & 4200.65 & 1.65 & 361.27
\end{tabular}

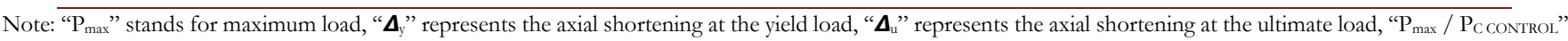
indicates the change in the maximum load after using SM compared to the control specimen, and "DI" refers to ductility index.

Table 4: fundamental experimental outcomes for every tested column specimen.

\section{Load versus vertical shortening curves and maximum load}

The vertical shortening increases swiftly with raising the value of the applied load prior to reaching the maximum load. Then, due to the concrete cover spalling and the starting of concrete crushing, the column compression load dropped after overtaking the maximum load with increasing the vertical shortening; Fig. 21. The diminishing trend of the load-shortening curve for the control concrete column specimen was more obvious after the peak of the curve being reached than that for the concrete column specimens, which were confined using both stirrups and steel mesh, as indicated in Fig. 21. This shows the increase of deformation capacity for confined column specimens using SM compared to the control column specimen. Thus, the deformability beside the energy absorption increased remarkably by reinforcing the circular column using steel mesh. The highest deformability after the maximum load being achieved was observed by wrapping either double wraps from the steel mesh over the stirrups as a partial confinement pattern or a single wrap from the steel mesh around the reinforcing cage as a full confinement pattern; specimens (CS2OC and CFOC), respectively, as shown in Fig. 21(a). 


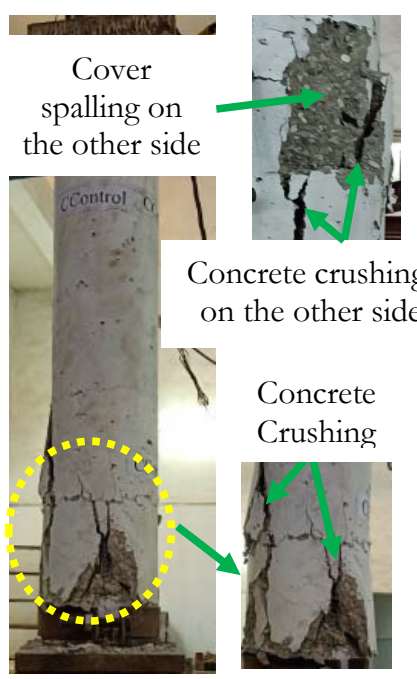

(a) C CONTROL

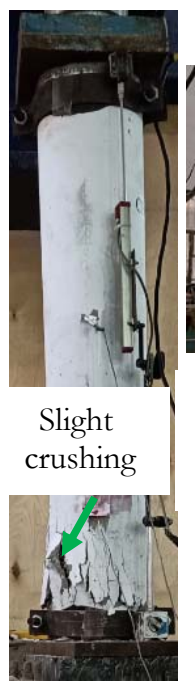

(d) $\mathrm{CFOC}$

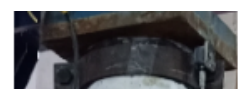

Concrete crushing on the other side

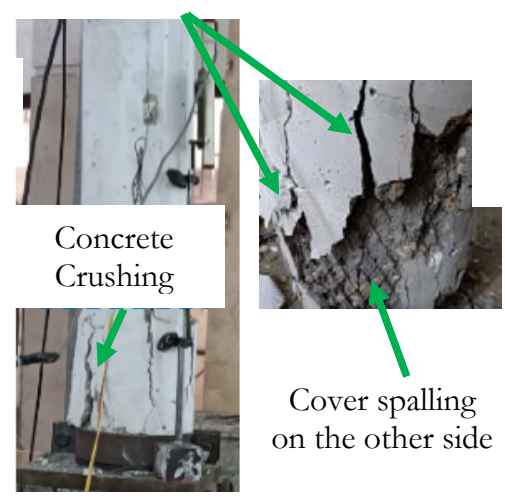

(b) CS1OC
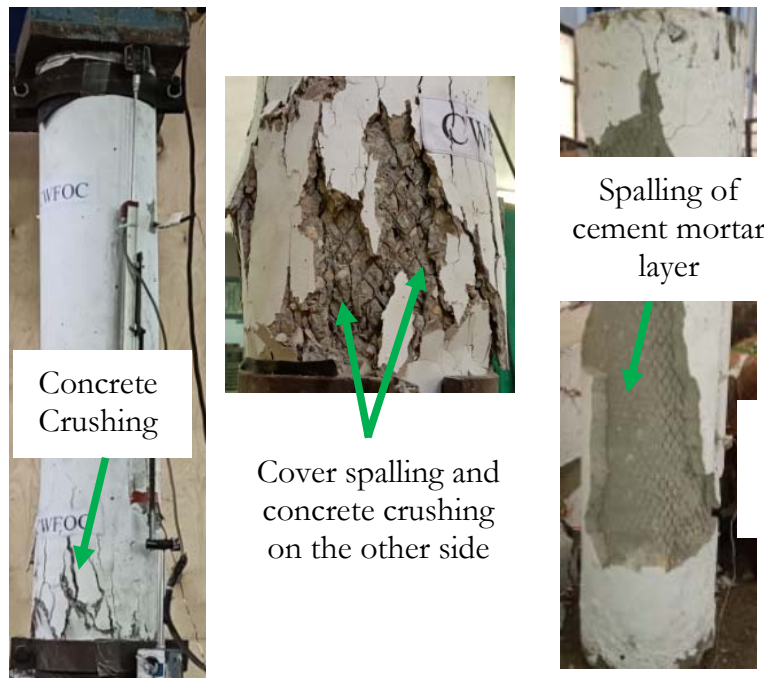

Spalling of cement mortar layer

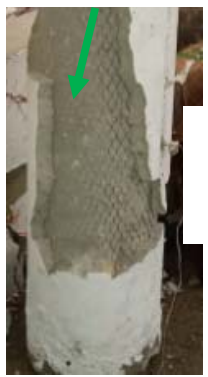

Cover spalling and concrete crushing on the other side

(e) CWFOC

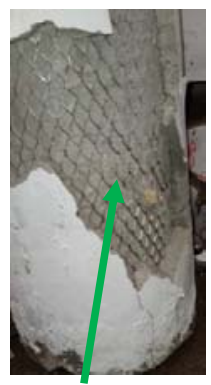

Spalling of cement mortar layer on the other side

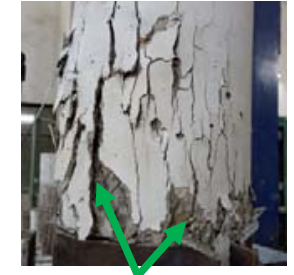

Limited cover spalling and slight crushing on the other side

Limited rupture of EMM strands

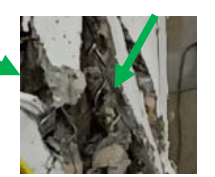

(c) $\mathrm{CS} 2 \mathrm{OC}$

(F) CFED

Figure 20: Crack patterns and failure modes of column specimens.

Fig. 23 and Tab. 4 reveal that all the studied parameters in the applying of SM as transverse confinement in addition to the stirrups for circular column samples could bear higher loading capacity with adequate ductility over the control circular column sample (including stirrups only without steel meshes), where the SM gives perfect confinement. Fig. 23 and Tab. 4 show that the heights load carrying capacity was observed in the case of specimen partially confined using two layers of steel mesh around the stirrups (specimen CS2OC). This result confirms that the load capacity of internally confined columns increases when the volumetric ratio of lateral confining reinforcement increases.

For the control column specimen the experimental load carrying capacity was about $680 \mathrm{kN}$ which was $2.7 \%$ higher than the theoretical load carrying capacity $(662 \mathrm{kN})$ calculated according to the Egyptian standards. In the case of the internal confinement, the maximum load for the confined column specimens using single or double wrapping layers of SM as partial confinement over the stirrups surpassed that of the control column sample by $10.03 \%$ and $15.91 \%$, respectively; specimens (CS1OC and CS2OC), as shown in Fig. 21 (a) and Fig. 23. The maximum load also increased when reinforcing the column using SM as full confinement over the stirrups (internal confinement); specimen (CFOC) by about 13.37\%; Fig. 21 (a) and Fig. 23. 
Using SM as full internal confinement rather than the classical stirrups; specimen (CWFOC) resulted in a very slight decrease in loading capacity by about $0.87 \%$ less than the original control column capacity (with stirrups only), where this specimen achieved a loading capacity of about $674.1 \mathrm{kN}$, as indicated in Fig. 21(b) and Tab. 4. This demonstrates the superb efficiency of steel mesh to confine the concrete circular column core rather than the classical stirrups, which has a higher cost than the steel mesh. In other words, a large reduction in the volumetric ratio of the stirrups with no significant loss in ultimate capacity could be achieved by wrapping the EMM layer around the main reinforcement. In the case of the external jacketing, using one wrap of SM around the outer perimeter of the column; specimen (CFED), increased the maximum load by $10.25 \%$ compared to the original specimen, as shown in Fig. 21(c) and Fig. 23.

In general, the analysis of the test results above showed that the utilization of the steel mesh in reinforcing the circular concrete column internally over the classical stirrups or in strengthening it externally enhanced the column behavior; Fig. 21. The results also exhibited that using steel mesh as full internal confinement achieved a relatively greater effect in increasing the loading capacity for the circular column than that achieved by using steel mesh as a full external jacketing; Figs. 22 and 23. This result agrees with the research introduced by El-Kholy and Dahish [22], which showed a significant improvement in the ultimate load of the RC columns by using steel mesh as internal confinement.

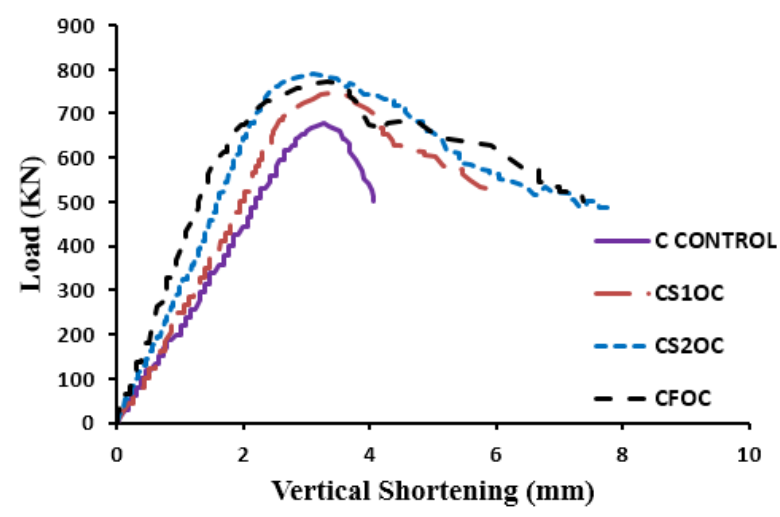

(a) Effect of internal confinement using SM.

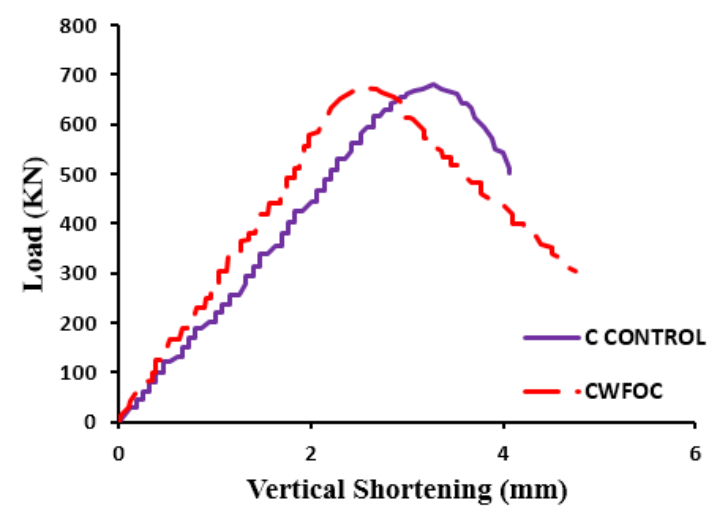

(b) Effect of replacing the stirrups with SM.

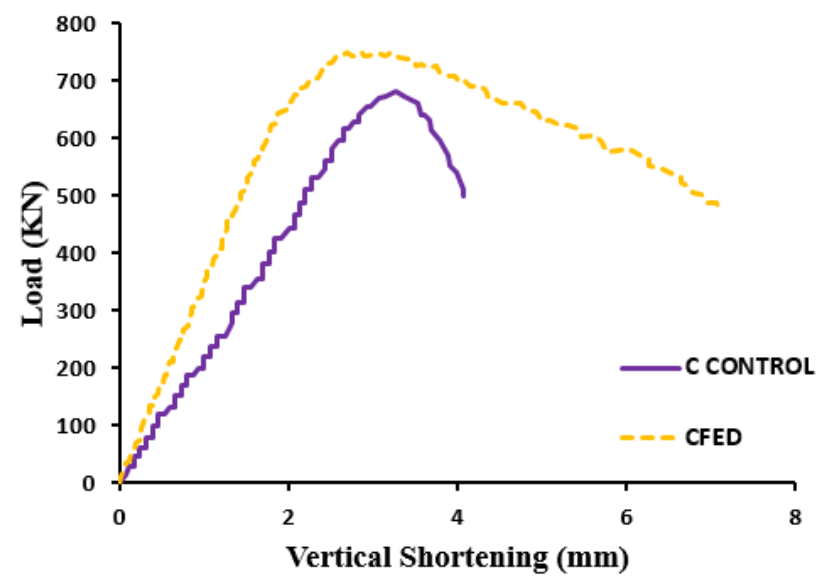

(c) Effect of external jacketing using SM.

Figure 21: Load versus mid-hight vertical shortening curves for the tested columns.

\section{Ductility index}

The ductility of the structures is the capability of the member in the structure to withstand inner forces with high deformation, where the calculation of the ductility value can be a forthright reflection for the determination of the capacity of plastic deformation respecting the column samples. For this reason, a common method was used in the present analysis to get the ductility factor. This method is a calculation of the proportion between the axial shortening at the ultimate load 


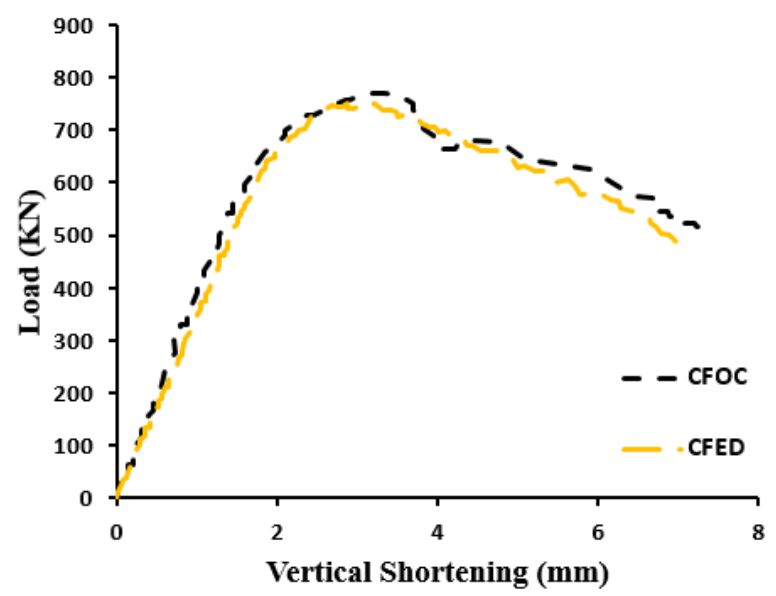

Figure 22: Comparison between load-vertical shortening curves of full internal and full external confinement for the circular column using SM.

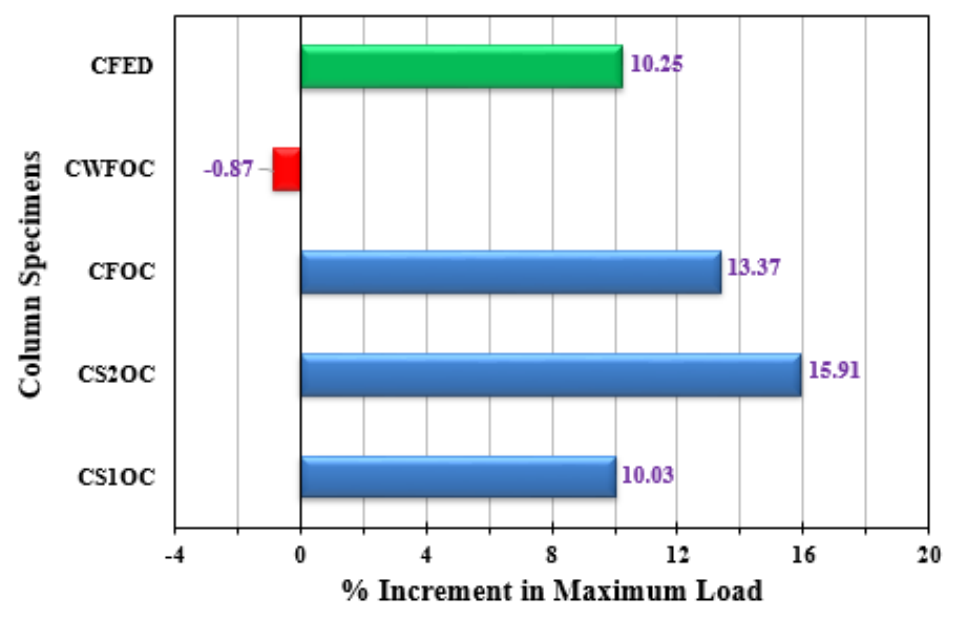

$\square$ Intemal confinement $\boxminus$ Replacing the stirrups with SM $₫$ External confinement

Figure 23: Percentage increase in the maximum load of the confined column specimens compared to the control column specimen.

" $\boldsymbol{\Delta}_{\mathrm{u}}$ " and that at the yield load " $\boldsymbol{\Delta}_{\mathrm{y}}$ " as shown in Eq. (1). This method is known as ductility index "DI".

The load-shortening curves in Fig. 21 demonstrate that the column specimens which were confined with the various schemes of steel mesh beside the classical stirrups showed enhanced ductility compared to that of the control column specimen. The ductility index increments of all the studied confined specimens were indicated in Fig. 24, and its values were illustrated in Tab. 4. The enhancement was very significant in case of the full confinement over the stirrups; specimen (CFOC), and medium in case of the partial confinement (single or double wraps of SM) over the stirrups; specimens (CS1OC and CS2OC). Where the ductility index for the specimens CS1OC, CS2OC, and CFOC increased by about 12.17\%, 14.78\%, and $54.78 \%$ compared to the control specimen (C CONTROL), respectively, while replacing the stirrups with a single wrap of steel mesh around the entire longitudinal reinforcing steel as in the specimen (CWFOC) not only maintained the ductility level of the column but there was a slight improvement in the value of the ductility index by about 2.61\%; Fig. 24. This shows the effectiveness of increasing the volumetric ratio of mesh reinforcement as lateral confining in the same position of the reinforcement in increasing the ductility index of the column specimen, as in the specimens CS1OC and CS2OC.

It should be noted that the full external jacketing around the outer perimeter of the column; specimen (CFED) also improved the ductility index by $43.48 \%$. This refers to that using steel mesh as full internal reinforcement for the circular column can enhance the ductility by a greater ratio to some extent than that accomplished by using it as full external strengthening, as shown in Fig. 24. This may be attributed to the fact that the full internal reinforcement greatly reduced the regions of concrete cover spalling and diminished the severity of concrete crushing; Fig. 20(d). 


$$
D I=\Delta_{u} / \Delta_{y}
$$

\section{Energy absorption}

Another method for calculating ductility factor, which is known as energy absorption capacity, was considered in the current study. This method is a computation of the entire area under the load-vertical shortening curve via numerical integration to foresee the sample ductility based on the study presented by Hadi [38, 39].

All internally or externally confined column specimens absorbed energy larger than that for the control specimen, as Fig. 25 and Tab. 4 clarify. Fig 25 displays that the increase in energy absorption of column specimen CS2OC was more than those for other column specimens due to the slight deterioration of this specimen. The highest loading capacity was provided via the same specimen, as mentioned earlier. The percentages of energy absorption increase in the case of the internal confinement beside the traditional stirrups were $79.34 \%$ for specimen CS1OC (partial confinement using a single wrap of steel mesh), $162.86 \%$ for specimen CS2OC (partial confinement using a double wrap of steel mesh), and 162.18\% for specimen CFOC (full confinement using a single wrap of steel mesh) compared to control specimen; Fig. 25. While the energy absorption in the case of absence of the stirrups; specimen CWFOC (full internal confinement using a single wrap of steel mesh without stirrups) increased slightly by about $19.15 \%$, this may be attributed to the crushing in this specimen was higher than other confined column specimens. The full external jacketing using SM; specimen CFED also increased the energy absorption by $150.72 \%$, as indicated in Fig. 25.

\section{Stiffness}

In the current study, the stiffness value of RC column specimens was calculated as the slope of the load-vertical shorting curve in the elastic region (linear region). Where the stiffness is the ratio between the change in load capacity to change in the shortening. Fig. 21 and Tab. 4 showed that the CS1OC specimen could present slight enhancement (or no degradation at least) in the stiffness, while the CS2OC specimen and the CWFOC specimen revealed medium enhancement in column stiffness over that of the control specimen (C CONTROL). Finally, whether the full internal or external confinement, in addition to the classical stirrups; specimens CFOC and CFED, presented a noticeable enhancement in the stiffness. These results illustrate that the confinement of circular columns using steel mesh has an effective role in their stiffness. Where using the steel mesh led to increasing the stiffness of all tested column samples. For further clarification, the stiffness of specimens CS1OC, CS2OC, CFOC, CWFOC, and CFED increased by $13.46 \%, 28.47 \%, 51.17 \%, 24.97 \%$, and 47.79 \%compared to the control specimen, respectively; Fig. 26.

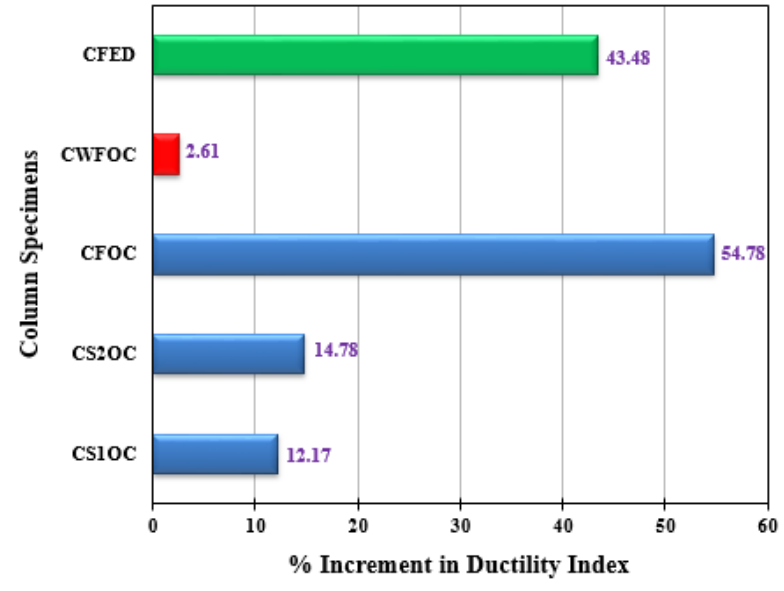

IIntemal confinement $\square$ Replacing the stirrups with SM $₫$ External confinement

Figure 24: Percentage increase in the ductility index of the confined column specimens compared to the control column specimen.

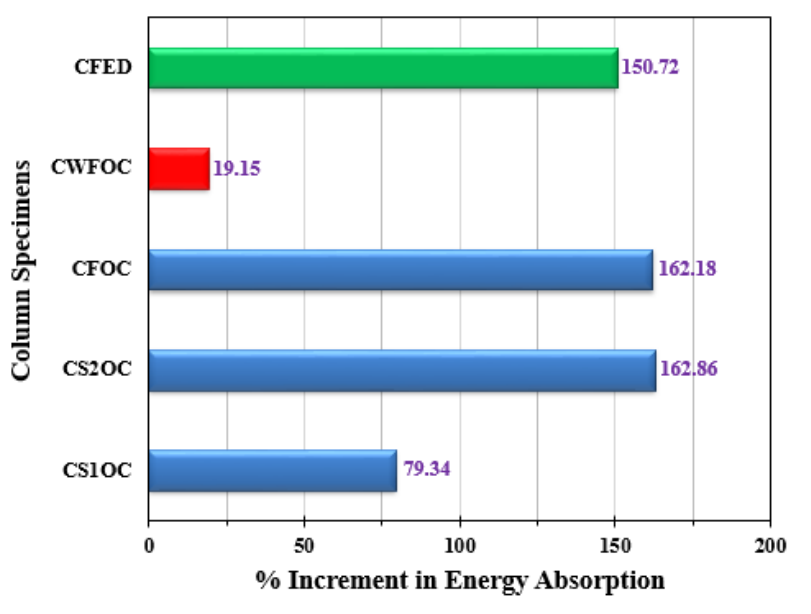

Internal confinement $\square$ Replacing the stirrups with SM $₫$ External confinement

Figure 25: Percentage increase in the energy absorption of the confined column specimens compared to the control column specimen. 


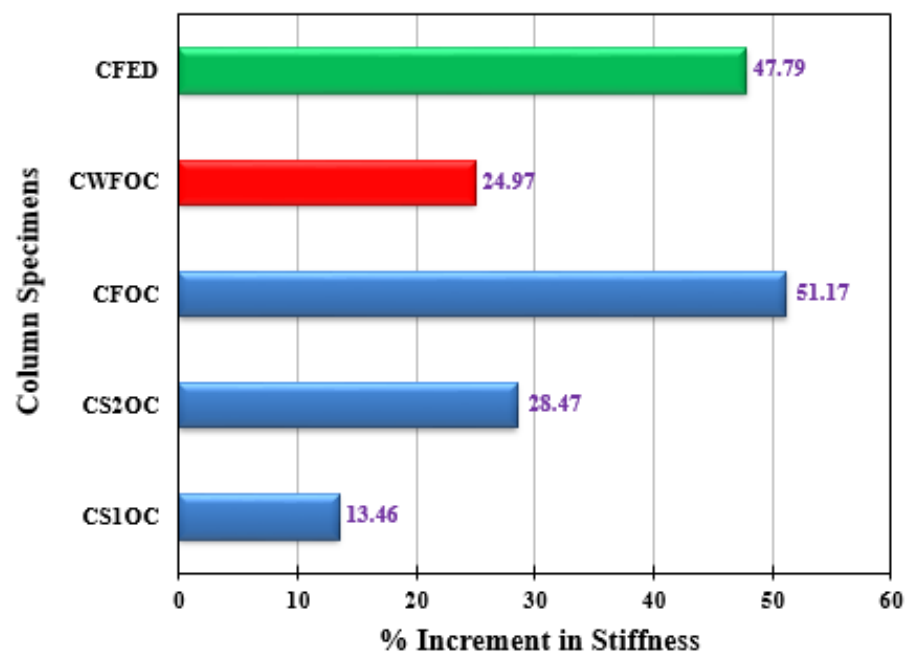

$\square$ Internal confinement $\square$ Replacing the stirrups with SM $\square$ External confinement

Figure 26: Percentage increase in the stiffness of the confined column specimens compared to the control column specimen.

\section{Load versus axial strain}

Fig. 27 confirms that using double layers of EMM as a partial internal confinement pattern for the column specimen presented the highest vertical strain increment; specimen CS2OC compared to the other confined specimens with respect to control column specimen (C CONTROL). Also, it should be noted that the case of using EMM layer as full confinement either internally or externally led to a significant increase in the vertical strain value of the confined columns; specimens CFOC and CFED.

The increments of vertical strain for the column specimens partially confined using the EMM was greatly affected by the number of mesh layers, where the vertical strain increase was $26.69 \%$ in case of using a single layer of EMM; specimen CS1OC and $45.63 \%$ in case of using double layers of EMM; specimen CS2OC. Whereas the increments of vertical strain for the column specimens fully confined using the EMM layer were $42.72 \%$ for the internal confinement; specimen CFOD, and $36.89 \%$ for the external confinement; specimen CFED. A small reduction was observed in the vertical strain value with about $6.31 \%$ when using a single layer of EMM around the main reinforcing steel instead of the traditional stirrups; specimen CWFOC.

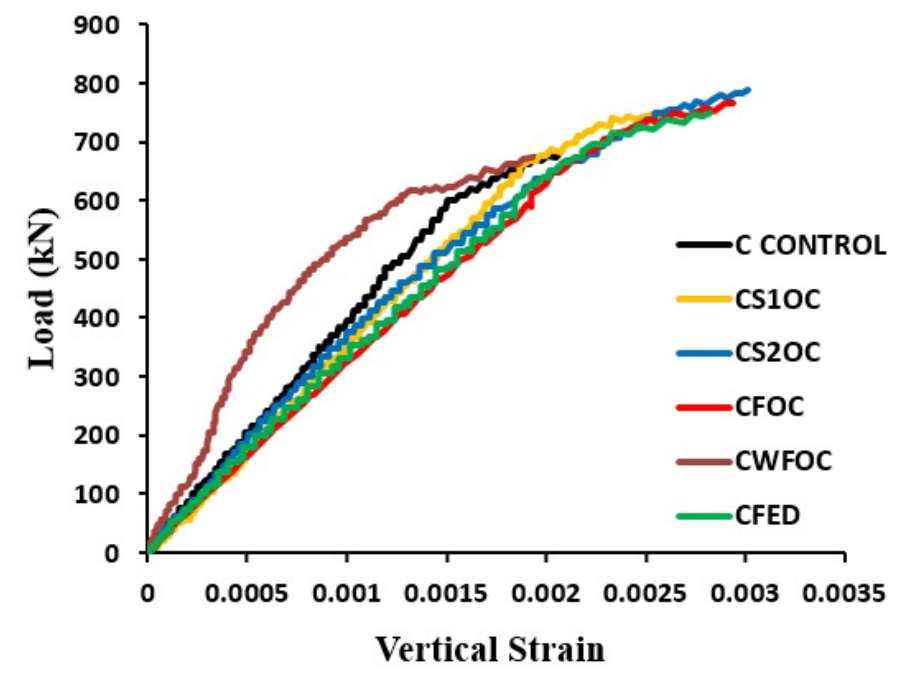

Figure 27: Load-vertical strain relationship for the tested column specimens. 


\section{CONCLUSIONS}

$\mathrm{T}$ his paper presented an experimental test to evaluate the behavior of circular $\mathrm{RC}$ columns that were confined internally or externally using steel mesh (SM). Six short RC circular column specimens were tested under central loading until the failure, including one as a reference specimen, and the rest were confined with steel mesh. Various parameters including, SM schemes, number of SM wraps, SM position (internally or externally), and the steel stirrups existence, were studied in the current research. As a result of the experimental test procedure in this study, the subsequent conclusions were obtained:

- The failure mode for the control column specimen was a somewhat brittle failure, whereas using SM as internal or external jacketing for the remaining column specimens presented a noticeable deformation capacity and enhanced ductility, where the diminishing trend of the load-shortening curve for the confined column specimens was less obvious after the peak of the curve being reached than that for the control column specimen.

- Using SM in addition to the stirrups gives better confinement than that in the case of using the stirrups only. Where using double wraps of Expanded Metal Mesh (EMM) as partial internal confinement or using a single wrap of it as full internal confinement led to reducing the zones of concrete cover spalling, decreasing the severity of the deterioration of concrete crushing, and presenting the highest deformability after the maximum load being achieved.

- Externally fully jacketing using a single wrap of EMM showed influential confinement, where the failure occurred in the cement mortar layer around the steel mesh, but the internal core stayed intact.

- The confined column specimens could bear higher loading capacity with adequate ductility over the control specimen. The largest capacity was obtained by using double wraps of SM over the stirrups as a partial confinement pattern, where the maximum load surpassed that of the control specimen by about $15.91 \%$. However, the maximum ductility was observed in the case of the full internal confinement ( $54.78 \%$ increase over the control specimen).

- Using SM as full internal confinement rather than the classical stirrups demonstrated a superb efficiency to confine the RC circular column, where the column could recover $99.13 \%$ of the original control column capacity without a reduction in the original ductility value.

- Using SM as full internal confinement achieved a relatively greater effect in increasing the loading capacity and the ductility for the circular column than that achieved by using it as a full external jacketing.

- In general, increasing the volumetric ratio of mesh reinforcement in the same position of the confinement increases the effectiveness of the reinforcement and thus increases the value of the column capacity and enhances the ductility.

- All confined column specimens absorbed energy larger than that for the control sample, especially when using double wraps of SM as partial internal confinement, where the energy absorption increased by $162.86 \%$ due to the slight deterioration in this arrangement.

- Confinement of the circular RC column specimens using the SM led to increasing the column stiffness over the control specimen, especially when using SM as a full jacketing either internally or externally.

\section{REFERENCES}

[1] Lorenzis, L. D. and Teng, J. G. (2007). Near-surface mounted FRP reinforcement: An emerging technique for strengthening structures, Composites Part B: Engineering, 38(2), pp.119-143.

DOI: 10.1016/j.compositesb.2006.08.003.

[2] Jumaat, M. Z. and Alam, M. A. (2009). Strengthening of R.C. beams using externally bonded plates and anchorages, Australian Journal of Basic and Applied Sciences, 3(3), pp. 2207-2211. http://eprints.um.edu.my/6081.

[3] Wu, Y. F. and Jiang, C. (2013). Quantification of bond-slip relationship for externally bonded FRP-to-concrete joints, Journal of Composites for Construction, 17(5), pp. 673-686. DOI: 10.1061/(ASCE)CC.1943-5614.0000375.

[4] Zhou, Y., Fan, Z., Du, J., Sui, L. and Xing, F. (2015). Bond behavior of FRP-to-concrete interface under sulfate attack: an experimental study and modeling of bond degradation, Construction and Building Materials, 85, pp. 9-21.

DOI: 10.1016/j.conbuildmat.2015.03.031.

[5] Zhang, S.S., Yu, T. and Chen, G.M. (2017). Reinforced concrete beams strengthened in flexure with near-surface mounted (NSM) CFRP strips: current status and research needs, Composites Part B: Engineering, 131, pp. 30-42. DOI: 10.1016/j.compositesb.2017.07.072. 
[6] Hadad, H. A., Erickson, B. and Nanni, A. (2020). Flexural analysis and design of FRCM strengthened RC beams, Construction and Building Materials, 244, pp. 118371. DOI: 10.1016/j.conbuildmat.2020.118371.

[7] Yuan, F., Chen, M. and Pan, J. (2020). Flexural strengthening of reinforced concrete beams with high-strength steel wire and engineered cementitious composites, Construction and Building Materials, 254, pp. 119284. DOI: $10.1016 /$ j.conbuildmat.2020.119284.

[8] Hadi, M. N. S. (2007a). Behavior of FRP strengthened concrete columns under eccentric compression loading, Composite Structures, 77(1), pp. 92-96. DOI: 10.1016/j.compstruct.2005.06.007.

[9] Hadi, M. N. S. (2007b). The behavior of FRP wrapped HSC columns under different eccentric loads, Composite Structures, 78(4), pp. 560-566. DOI: 10.1016/j.compstruct.2005.11.018.

[10] Wu, H. L., Wang, Y. F., Yu, L. and Li, X. R. (2009). Experimental and computational studies on high-strength concrete circular columns confined by aramid fiber-reinforced polymer sheets, Journal of Composites for Construction, 13(2), pp. 125-134. DOI: 10.1061/(ASCE)1090-0268(2009)13:2(125).

[11] Chellapandian, M., Prakash, S. S. and Rajagopal, A. (2018). Analytical and finite element studies on hybrid FRP strengthened RC column elements under axial and eccentric compression, Composite Structure, 184, pp. $234-248$. DOI: $10.1016 /$ j.compstruct.2017.09.109.

[12] Hadi, M. N. S. and Zhao, H. (2011). Experimental Study of High-Strength Concrete Columns Confined with Different Types of Mesh under Eccentric and Concentric Loads, Journal of Materials in Civil Engineering, 23(6), pp. 823-832. DOI: $10.1061 /$ (ASCE)MT.1943-5533.0000234.

[13] Meng, Q., Chen, W. and Hao, H. (2017). Numerical and experimental study of steel wire mesh and basalt fibre mesh strengthened structural insulated panel against projectile impact, Advances in Structural Engineering, 21(8), pp.11831196. DOI: $10.1177 / 1369433217733762$.

[14] Kondraivendhan, B. and Pradhan, B. (2009). Effect of ferrocement confinement on behavior of concrete, Construction and Building Materials, 23(3), pp. 1218-1222. DOI: 10.1016/j.conbuildmat.2008.08.004

[15] Tawab, A. A., Fahmy, E. H. and Shaheen, Y., B. (2012). Use of permanent ferrocement forms for concrete beam construction, Materials and Structures, 45(9), pp. 1319-1329. DOI: 10.1617/s11527-012-9834-1.

[16] Fahmy, E. H., Shaheen, Y. B. I., Abdelnaby, A. M. and Zeid, M. N. A. (2014). Applying the ferrocement concept in construction of concrete beams incorporating reinforced mortar permanent forms, International Journal of Concrete Structures and Materials, 8(1), pp. 83-97. DOI: 10.1007/s40069-013-0062-z.

[17] Chen, G. F. (2010). Experimental study on axial compression behavior of steel wire confined concrete [Master Thesis]. China: Zhengzhou University.

[18] Kim, S. H. and Choi, J. H. (2010). Repair of Earthquake Damaged RC Columns with Stainless Steel Wire Mesh Composite, Advances in Structural Engineering, 13(2), pp. 393-402. DOI:10.1260/1369-4332.13.2.393.

[19] Kim, S. H. and Kim, D. K. (2011). Seismic retrofit of rectangular RC bridge columns using wire mesh wrap casing, KSCE Journal of Civil Engineering, 15(7), pp. 1227-1236. DOI: 10.1007/s12205-011-0881-x.

[20] Abo-AlAnwar, M. M. (2015). An Experimental Study On Strengthening Rectangular Reinforced Concrete Columns Under Eccentric Loads By Steel Wire Mesh And External Vertical Steel Bars, Civil Engineering Research Magazine (CERM), Al-Azhar University, Faculty of Engineering, Department of Civil Engineering, Cairo, Egypt, 36(4), pp. 280_ 296. https://www.researchgate.net/publication/329452895.

[21] Kumar, V. and Patel, P. V. (2016). Strengthening of axially loaded circular concrete columns using stainless steel wire mesh (SSWM) - Experimental investigations, Construction and Building Materials, 124, pp. 186-198. DOI: $10.1016 /$ j.conbuildmat.2016.06.109.

[22] El-Kholy, A. M. and Dahish, H. A. (2016). Improved confinement of reinforced concrete columns, Ain Shams Engineering Journal, 7(2), pp. 717-728. DOI: 10.1016/j.asej.2015.06.002.

[23] El-Kholy, A. M., Abd El-Mola, S., Abd El-Aziz, M. A. and Shaheen, A. A. (2018). Effectiveness of Combined Confinement with Metal Meshes and Ties for Preloaded and Post-Heated RC Short Columns, Arabian Journal for Science and Engineering, 43, pp. 1875-1891. DOI: 10.1007/s13369-017-2782-x.

[24] Marthong, C., Sutnga, D., Kharshandi, O., Khryiemmujat, I. G. and Shangpliang, A. (2019). Mechanical Strength of Galvanized Steel Wire Mesh (GSWM) as a Strengthening Material of Short RC Column, IOP Conference Series Materials Science and Engineering, 491, pp. 012014. DOI:10.1088/1757-899X/491/1/012014.

[25] Elsamny, M. K., Elbatal, S. A., Abo-Alanwar, M. M. and Abdel-Mohsen, A. M. (2020). Retrofitting Of Damaged RC Columns Using Spiral Stirrups, New York Science Journal, 13(3), pp.16-38. DOI:10.7537/marsnys130320.02.

[26] Griezic, A., Cook, W. D. and Mitchell, D. (1994). Tests to determine performance of deformed welded wire fabric stirrups, Structural Journal, 91(2), pp. 211-220. https://trid.trb.org/view/389106. 
[27] El Debs, M. K. and Naaman, A. E. (1995). Bending behavior of mortar reinforced with steel meshes and polymeric fibers, Cement and Concrete Composites, 17(4), pp. 327-338. DOI: 10.1016/0958-9465(95)00031-7.

[28] Paramasivam, P., Lim, C. T. E. and Ong, K. C. G. (1998). Strengthening of RC beams with ferrocement laminates, Cement and Concrete Composites, 20(1), pp. 53-65. DOI: 10.1016/S0958-9465(97)00068-1.

[29] Nithin, K. R. and Kumar, N. S. (2016). Flexural behaviour of self-compacting concrete beam using welded wire mesh as shear reinforcement, International Journal of Science and Research (IJSR), 5(6), pp. 189-194. DOI: $10.21275 /$ v5i6.NOV164026.

[30] Egyptian Code Committee. Egyptian code for design and construction of concrete structures; ECP 203-2007. Cairo (Egypt): Housing and Building National Research Center, HBRC; (2010).

[31] Egyptian Standards - Ferrous Products Committee. Steel for the reinforcement of concrete Part1: - Plain bars; ES 2621. Cairo (Egypt): Egyptian Organization for Standards and Quality, EOS; (2009).

[32] Egyptian Standards - Ferrous Products Committee. Steel for the reinforcement of concrete Part2: - Ribbed bars; ES 262-2. Cairo (Egypt): Egyptian Organization for Standards and Quality, EOS; (2009).

[33] Egyptian Standards - Building Materials Committee. Aggregates for concrete; ES 1109. Cairo (Egypt): Egyptian Organization for Standards and Quality, EOS; (2008).

[34] Egyptian Standards-Building Materials Committee: Cement Part 1: Composition, Specifications and Conformity Criteria for Common Cements (ES 4756-1). Egyptian Organization for Standards and Quality (EOS), Cairo (2013).

[35] British Standards - B/516/6 Cement Specifications Committee. Cement Part1: Composition, specifications and conformity criteria for common cements; BS EN 197-1. London (UnitedKingdom): British Standards Institution, BSI; (2011).

[36] Batson, G. B., Castro, J. O., Guerra, A. J., Iorns, M. E., Johnston, C. D., Naaman, A. E., ...and Tilsen, B. L. (1988). Guide for the design, construction, and repair of ferrocement, ACI Structural Journal, 85(3), pp. 325-351. https://www.concrete.org/publications/internationalconcreteabstractsportal/m/details/id/3527.

[37] Yanhua, S., Xiaoyong, W. and Guangjing, X. (2013). Seismic Behaviour of RC Columns Strengthened with Steel Bar/wire Mesh Mortar, Key Engineering Materials, 539, pp. 108-114. DOI: 10.4028/www.scientific.net/KEM.539.108.

[38] Hadi, M. N. S. (2006). Behaviour of FRP wrapped normal strength concrete columns under eccentric loading, Composite structures, 72(4), pp. 503-511. DOI: 10.1016/j.compstruct.2005.01.018.

[39] Hadi, M. N. (2007). Behaviour of FRP strengthened concrete columns under eccentric compression loading, Composite Structures, 77(1), pp. 92-96. DOI: 10.1016/j.compstruct.2005.06.007. 